\title{
A rare endoscopic feature of eosinophilic esophagitis
}

A 61-year-old woman without any significant past medical history, presented to the clinic with 3 months of heartburn, dysphagia, and recent regurgitation of food. She had taken antacids and acid suppressive therapy without improvement of her symptoms. She denied weight loss, melena, or nonsteroidal anti-inflammatory use. Her physical exam, including vitals and abdominal exam, was normal. Laboratory data including a complete blood count, and comprehensive metabolic panel, were all unremarkable. An upper endoscopy demonstrated multiple sessile polyps $<5 \mathrm{~mm}$ in diameter in the upper two-thirds of the esophagus, all of which were removed with cold forceps $(\bullet$ Fig. 1). Linear furrows were also noted throughout the esophagus. ( $\bullet$ Fig. 2). The rest of the upper gastrointestinal tract was normal. Histological examination of the esophageal polyps revealed polypoid squamous mucosa with increased numbers of intraepithelial lymphocytes and $>70$ eosinophils per high power field $(\bullet$ Fig. 3). The patient was subsequently placed on fluticasone, and on follow up all of her symptoms had resolved.

Eosinophilic esophagitis, first described in the 1970 s, is characterized by $>15$ eosinophils per high power field in concordance with symptoms of heartburn, regurgitation, dysphagia, or food bolus impactions [1]. The etiology is unknown but its strong association with atopic diseases such as food allergy, asthma, and eczema suggest an allergic pathway. Strictures are sometimes present, and typical endoscopic features described include horizontal rings, linear furrows, whitish exudates, granularity, and ulceration. Treatment options include elimination diets, inhaled or swallowed steroids, and other anti-inflammatory medications. Esophageal dilation must be done with great care, as perforation rates are probably higher in this population than with peptic or malignant strictures [2].

Our case had a unique endoscopic finding of esophageal polyps in the context of eosinophilic esophagitis. This is a rare finding, which has mostly been described in the pediatric literature [3]. There is no evidence to suggest that these polyps are premalignant; however, this case should heighten awareness of the association of

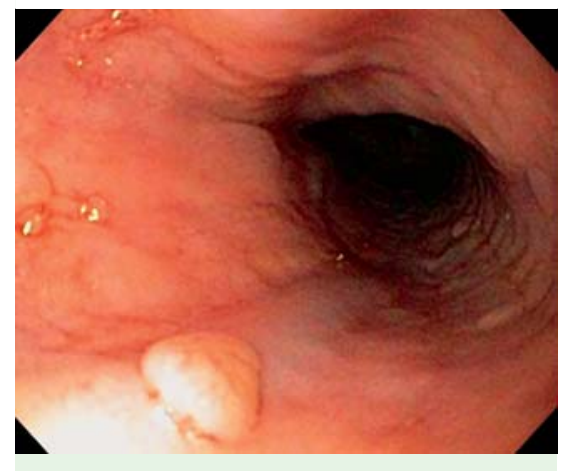

Fig. 1 Esophageal polyp and furrows.

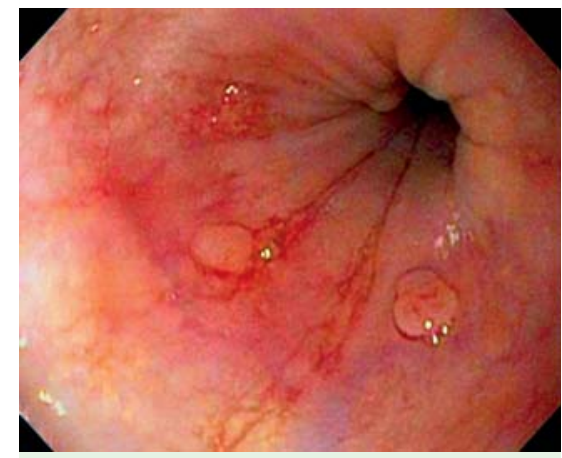

Fig. 2 Esophageal polyps with linear furrows.

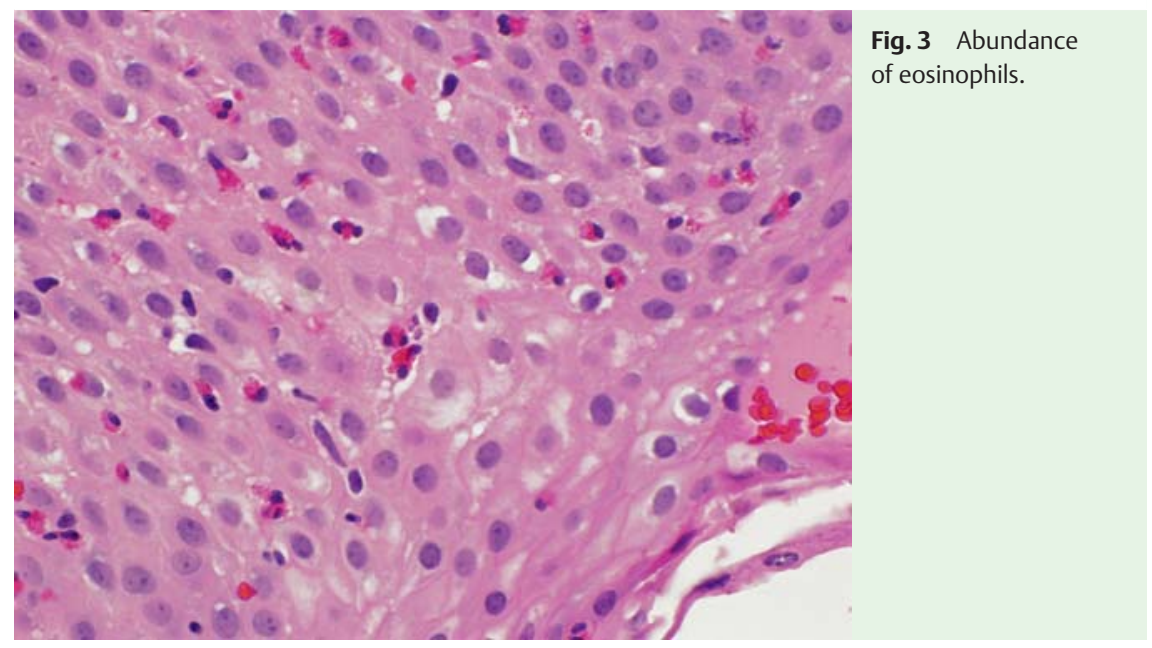

eosinophilic esophagitis with polyps of the esophagus.

Endoscopy_UCTN_Code_CCL_1AB_2AC_3AH

Competing interests: None

\section{J. A. Gill' ${ }^{1}$, J. Shutter ${ }^{2}$, P. Brady ${ }^{1}$}

${ }^{1}$ Division of Digestive Diseases, University of South Florida, Tampa, Florida, USA

2 Department of Pathology and Cell Biology, University of South Florida, Tampa, Florida, USA

\section{References}

1 Rothenberg ME. Eosinophilic gastrointestinal disorders. J Allergy Clin Imunol 2004; 113: $11-28$

2 Ferguson DD, Foxx-Orenstein AE. Eosinophilic esophagitis: an update. Dis Esophagus 2007; 20: 2-8

3 Mulder DJ, Gander S, Hurlbut DJ et al. Multiple squamous hyperplastic-fibrous inflammatory polyps of the oesophagus: a new feature of eosinophilic esophagitis? J Clin Pathol 2009; 62: 845-846

\section{Bibliography}

DOI $10.1055 / \mathrm{s}-0030-1255917$

Endoscopy 2011; 43: E17

(c) Georg Thieme Verlag KG Stuttgart · New York . ISSN 0013-726X

\section{Corresponding author}

\section{J. A. Gill}

University of South Florida

Division of Digestive Diseases

12901 Bruce B Downs Boulevard

Tampa

Florida 33612

USA

Fax: +813-974-2034

jeffreygill23@gmail.com 